\title{
What Can the Paris Agreement's Global Stocktake Learn from the Sustainable Development Goals?
}

Jennifer Huang*

In December 2018, countries will adopt the rules and guidelines that will bring the elements of the Paris Agreement to life. One key element is the global stocktake, a unique multilateral review mechanism focusing on collective action and achievement. Parties to the Paris Agreement may want to look to the United Nations (UN) Sustainable Development Goals (SDGs) and its High-level Political Forum on Sustainable Development (HLPF), which offer parallels to both the Agreement's enhanced transparency framework and the global stocktake. A review of the potential similarities and differences in their review and reporting cycles, their high-level events and outcomes, measuring progress, managing technical expert input, sharing knowledge, information and experience, as well as including non-state actors could provide some relevant lessons for the upcoming international climate negotiations. In some ways, the SDGs process is structurally and politically too dissimilar to offer a template but its approach to adaptation offers insight into how adaptation could be addressed in the global stocktake. Both processes also highlight the need to build the capacity of governmental processes to continuously improve the reporting of key information over time. Because these processes are complementary and meant to evolve, countries could begin to look to the long-term integration of aspects of both regimes to enhance coherence and reduce redundancies. At the climate conference in Katowice, Poland, Parties will need to narrow the broad outlines of the global stocktake down to specifics. Cycles need to be defined and ways to aggregate or synthesize the vast amounts of information must be determined. Parties can begin to draw on parallels between relevant processes and any early lessons they offer as they consider what key features to include in the modalities, rules, and guidelines to be decided in Katowice.

\section{Introduction}

The Paris Agreement establishes a global stocktake to periodically review Parties' collective progress towards achieving its global climate change goals. ${ }^{1}$ In global governance terms, the global stocktake is a multilateral review mechanism but one quite unlike those of other multilateral regimes. ${ }^{2}$ Most have been

DOI: $10.21552 /$ cclr/2018/3/8

* Jennifer Huang, International Fellow, Center for Climate and Energy Solutions (C2ES). For correspondence: <huangj@c2es.org $>$.

1 Paris Agreement (adopted 12 December 2015, entered into force 4 November 2016) 55 ILM 740 art 14. designed to review individual progress and none have long-term global goals with similar timeframes. ${ }^{3}$ What distinguishes the global stocktake process is the importance placed on driving ambitious climate action over time and its focus on collective rather than individual achievement. ${ }^{4}$

The United Nations (UN) Sustainable Development Goals (SDGs) and its High-level Political Forum
2 Manjana Milkoreit and Kate Haapala, 'Designing the Global Stocktake: A Global Governance Innovation' (C2ES 2017) <https://www .c2es.org/site/assets/uploads/2017/11/designing-the-global-stocktake -a-global-governance-innovation.pdf> accessed 15 August.

3 ibid 1, 5 .

4 Paris Agreement (n 1) art 14. 
on Sustainable Development (HLPF) offer some interesting parallels to both the Paris Agreement's enhanced transparency framework and global stocktake. The SDGs processes review Member States' actions, qualitatively and quantitatively, to assess collective progress towards the Goals. Engaging in the SDGs process is both a management tool, helping countries develop implementation and monitoring strategies for achieving the SDGs, and a report card, measuring progress towards achieving the Goals. ${ }^{5}$

This article explores the similarities and differences between the SDG and HLPF processes and the broad outlines of the Paris Agreement's global stocktake, drawing some key lessons learned and identifying potential opportunities for complementary evolution.

\section{Measuring Collective Achievement and Enhancing Implementation and Ambition}

International environmental lawyers may be more familiar with traditional accountability frameworks

5 Leadership Council of the Sustainable Development Solutions Network, 'Indicators and a Monitoring Framework for the Sustainable Development Goals: Launching a Data Revolution for the SDGs' (2015) < https://sustainabledevelopment.un.org/content/ documents/2013150612-FINAL-SDSN-Indicator-Report1.pdf> accessed 15 August.

6 Conventionally, punitive measures include the withdrawal of benefits and/or the application of penalties or sanctions.

7 Geir Ulfstein and Jacob Werksman, 'The Kyoto Compliance System: Towards Hard Enforcement' in Jon Hovi, Olav Stokke and Geir Ulfstein (eds), Implementing the Climate Regime: International Compliance (Earthscan 2005).

8 Paris Agreement (n 1) art 4(2)

9 ibid art 13

10 ibid art 15

11 ibid art 14(2).

12 ibid art 14(3).

13 ibid art 14(2).

14 UNFCCC 'Decision 1/CP.21, Adoption of the Paris Agreement' UN Doc FCCC/CP/2015/10/Add.1 (29 January 2016) para 115.

15 UNFCCC 'Decision 1/CP.23, Fiji Momentum for Implementation' UN Doc FCCC/CP/2017/11/Add.1 (8 February 2018) Annex II, paras 10-11.

16 F Lesniewska and L Siegele, 'The Talanoa Dialogue: A Crucible to Spur Ambitious Global Climate Action to Stay Within the $1.5^{\circ} \mathrm{C}$ Limit' (2018) 12 CCLR 41.

17 UNFCCC 'Draft Conclusions Proposed by the Co-Chairs' (10 May 2018) UN Doc FCCC/APA/2018/L.2/Add.1 (10 May 2018) 123.

18 'The Millennium Development Goals' (United Nations Foundation) <http://www.un.org/millenniumgoals/> accessed 15 August. enforced by punitive measures, ${ }^{6}$ as exemplified by the Kyoto Protocol, ${ }^{7}$ but the Paris Agreement takes a new approach, tying together complementary processes in a cyclical system. The global stocktake is a crucial piece of that framework, together with the regular submission of nationally determined contributions (NDCs), ${ }^{8}$ an enhanced transparency process that requires each Party to report on their action and support every two years, ${ }^{9}$ and an implementation and compliance committee, whose functions have yet to be negotiated but are meant to be facilitative rather than punitive. ${ }^{10}$

To raise ambition, every five years Parties will conduct a global stocktake of collective progress toward the Agreement's long-term goals (LTGs) on mitigation, adaptation and support. ${ }^{11}$ The outcome will inform Parties' submission of a new NDC two years later. ${ }^{12}$ The first stocktake is set for $20233^{13}$ but Parties at the Paris conference decided to kickstart the process with a 'facilitative dialogue' in $2018 .{ }^{14}$ Rechristened the Talanoa Dialogue by the Fijian presidency and similar to but more limited in scope than the global stocktake, it will run through the year and culminate at the $24^{\text {th }}$ Conference of the Parties (COP 24) to the United Nations Framework Convention on Climate Change (UNFCCC) in Katowice, Poland. ${ }^{15}$ It is intended to inform the new or revised NDCs Parties will submit by 2020 and could offer lessons for the design of future global stocktakes. $^{16}$

UNFCCC Parties are currently negotiating the framework and modalities for the global stocktake, aiming for key decisions at the end of 2018. A broad outline is taking shape: a preparatory phase in which information is gathered and compiled; a technical phase in which inputs are considered; and a political phase concluding the stocktake. ${ }^{17}$ But crucial issues remain to be addressed. Because Parties will report on domestic action and progress, how will the global stocktake assess collective progress towards the LTGs? Parties also want to reflect the principle of equity in the global stocktake process but diverge on how it can be operationalized. A third question is defining where the stocktake links to other major elements of the Paris Agreement framework and elaborating the details of those linkages.

Separately, the UN set out the 17 SDGs (also known as the Global Goals) in 2015, to build on the success of the Millennium Development Goals, ${ }^{18}$ including new areas such as climate change and sustainable 
consumption. ${ }^{19}$ All UN Members are invited to make efforts to achieve those goals. An annual HLPF provides a public opportunity to voluntarily highlight individual achievements and concludes with a highlevel report from the Secretary-General describing progress towards the SDGs.

\section{Comparing the SDGs, HLPF, and the Global Stocktake}

The SDGs and global stocktake processes broadly share the same objectives: measuring collective progress, providing an opportunity for experienceand lessons-sharing, and enhancing implementation and ambition. ${ }^{20}$ Therefore, a review of their potential similarities and differences in how they function, their methodology, inputs and outputs, and key actors ought to provide some relevant lessons for the negotiations on the global stocktake. A review is timely: as of July, the SDGs process finished its fourth HLPF since the adoption of the SDGs in $2015 .{ }^{21}$ This article compares key elements of the SDG process with those being negotiated or decided for the global stocktake.

\section{Measuring Progress}

There are 17 SDGs, each with their own set of targets and indicators. ${ }^{22}$ The indicators are tiered based on their level of methodological robustness and the availability of data globally. For most indicators, the values represent global, regional and sub-regional aggregates and are calculated from data from national statistical systems, compiled by international agencies and often adjusted to allow for international comparability or supplemented by estimates where data is lacking. ${ }^{23}$ The indicators, targets, and goals together serve as an organizing framework for action.

The global stocktake will be an opportunity to measure UNFCCC Parties' progress against the LTGs of the Paris Agreement, though those goals for adaptation and finance are not well-defined and not measurable in the same way emissions reductions can be correlated to the temperature goal. ${ }^{24}$ While it is generally assumed that each Parties' reported greenhouse gas emissions inventories will be tallied and measured against the temperature goal, as of writing
Parties have not yet agreed on the ways that the global stocktake will measure progress towards the LTGs, particularly with respect to adaptation or finance.

\section{Timing and Review Cycle}

Each year, five to six SDGs are reviewed at the HLPF under the UN Economic and Social Council (ECOSOC) or UN General Assembly, completing all 17 SDGs every four years. There is no pause in the review process, with a high-level event occurring every year.

While the Paris Agreement mandates that the global stocktake occur every five years, Parties are considering just how long the stocktake process itself should be, given timing and resources. According to the early options drafted by Parties at the UNFCCC sessions in Bonn in May 2018 (Bonn informal notes), Parties are largely envisioning a one- to twoyear process from start to finish. ${ }^{25}$

\section{Reporting}

In the SDGs process, all government reporting is strictly voluntary; the UN encourages regular and inclusive country progress reviews but does not stipulate their frequency. ${ }^{26}$ Where a Member State wish-

19 United Nations Development Programme, 'Background on the Goals' <http://www.undp.org/content/undp/en/home/sustainable -development-goals/background.html> accessed 15 August.

20 Sustainable Development Knowledge Platform, 'Objectives' $<$ https://sustainabledevelopment.un.org/hlpf\#objectives> accessed 15 August; Paris Agreement (n 1) art 14.

21 ECOSOC 'Ministerial declaration of the high-level segment of the 2018 session of the Economic and Social Council on the annual theme 'From global to local: supporting sustainable and resilient societies in urban and rural communities', 'Ministerial declaration of the 2018 high-level political forum on sustainable development, convened under the auspices of the Economic and Social Council, on the theme 'Transformation towards sustainable and resilient societies" UN Doc E/HLS/2018/1 (1 August 2018).

22 Sustainable Development Knowledge Platform, 'Sustainable Development Goals' < https://sustainabledevelopment.un.org/sdgs $>$ accessed 15 August.

23 ECOSOC 'Progress Towards the Sustainable Development Goals' UN Doc E/2018/64 (10 May 2018) 1

24 Paris Agreement (n 1) arts 2, 4, 7 and 9; Decision 1/CP.21 (n 13) para 53.

25 Draft Conclusions Proposed by the Co-Chairs (n 15) 123.

26 United Nations Development Group, 'Guidelines to Support Country Reporting on the Sustainable Development Goals' (2017) 16 
es to be reviewed on the SDGs, it can submit a voluntary national review (VNR) synthesis report on, inter alia, the status of their progress towards the SDGs, several examples of good practices, challenges encountered, and areas in which it needs additional support. Over a week at the HLPF, governments give a 30-minute presentation of their VNR report. ${ }^{27}$ In addition to individual national reports, the HLPF accepts input by Regional Commissions. ${ }^{28}$

Every five years, the Paris Agreement requires Parties to submit an NDC, or a Party's commitment to reduce greenhouse gas emissions and adapt to the impacts of climate change. ${ }^{29}$ Parties are also mandated to report at least biennially through the enhanced transparency framework on their actions and support, as well as through the national communications required every four years under the Convention. ${ }^{30}$ The Agreement states that the purpose of the transparency framework is to provide a clear understanding of climate change action and to track progress towards Parties' achievement of their NDCs to inform the global stocktake. ${ }^{31}$ Parties' reports will then undergo both a technical expert review and peer review process. $^{32}$

27 Sustainable Development Knowledge Platform, 'Voluntary National Reviews Database' <https://sustainabledevelopment.un.org/ vnrs/> accessed 15 August.

28 United Nations Regional Commissions, 'Regional Forums on Sustainable Development' <http://www.regionalcommissions.org/ regional-forums-on-sustainable-development> accessed $15 \mathrm{Au}$ gust.

29 Paris Agreement (n 1) art 4(2).

30 UNFCCC 'Decision 1/CP.17, Outcome of the Work of the Ad Hoc Working Group on Long-term Cooperative Action under the Convention' UN Doc FCCC/CP/2011/9/Add.1 (15 March 2012) para 90.

31 Paris Agreement (n 1) art 13(5) (emphasis added).

32 ibid art 13(11-12). See also Christopher Campbell-Duruflé, 'Rain or Sunshine in Katowice? Transparency in the Paris Agreement Rulebook' (2018) 12 CCLR

33 Draft Conclusions Proposed by the Co-Chairs (n 15) 123-128.

34 Decision 1/CP.21 (n 13) para 99.

35 Sustainable Development Knowledge Platform, 'High-Level Political Forum' <https://sustainabledevelopment.un.org/hlpf $>$ accessed 15 August.

36 United Nations Regional Commissions (n 26).

37 Draft Conclusions Proposed by the Co-Chairs (n 15) 128.

38 UN General Assembly 'Transforming Our World: the 2030 Agenda for Sustainable Development' UN Doc A/RES/70/1 (21 October 2015) para 83 (Transforming Our World).

39 United Nations, 'The Sustainable Development Goals Report 2018' (2018) <https://unstats.un.org/sdgs/files/report/2018/ TheSustainableDevelopmentGoalsReport2018-EN.pdf > accessed 15 August.
Parties are converging around a multi-phased global stocktake process, in which the first two preparatory and technical phases will gather information before compiling and 'considering' it. ${ }^{33}$ They are also further refining a non-exhaustive list of inputs, which will include outside sources like the Intergovernmental Panel on Climate Change (IPCC) reports but must define whether outputs from other Paris processes will link to the stocktake. ${ }^{34}$

\section{High-Level Event(s)}

To review progress, the HLPF annually discusses five to six SDGs and their interlinkages, meeting under the ECOSOC for eight days, including a three-day ministerial segment, and every four years at the level of Heads of State and Government under the General Assembly for two days. ${ }^{35}$ Five Regional Forums on Sustainable Development review progress on the SDGs and offer an opportunity for countries to share lessons learned, best practices, and challenges in implementation. $^{36}$

To raise the profile of climate action, UNFCCC Parties seem inclined for a final, political phase of the global stocktake to take on a role similar to that of the HLPF. However, it would not likely be a standalone event but take place during a COP meeting. The length of the event is under debate, from a single day to the entirety of the COP session. Like the HLPF, Parties are considering this event or event series to involve ministers. ${ }^{37}$

\section{Outcome(s)}

Each year, the HLPF concludes with an intergovernmentally negotiated joint ministerial declaration featuring a list of priorities. The UN Secretary-General also releases a high level, largely narrative report with some statistics outlining progress on the thematic SDGs for that year. The report also summarizes how countries are improving their data management, monitoring and accountability systems and methodology. ${ }^{38}$ In the 2018 report, four paragraphs are dedicated to efforts on climate change, mostly referencing action under the UNFCCC. ${ }^{39}$

The Bonn informal notes reveal Parties are considering a range of potential outputs for the global stocktake, from high-level events (options include a dedi- 
cated political ministerial segment, high-level ministerial dialogues or roundtables), a presidential statement or final report, a summary of key messages, a decision by the COP serving as meeting of the Parties to the Paris Agreement, or a formal declaration. ${ }^{40}$ A combination of the above is also possible. Given that the stated purpose of the outcome of the global stocktake is to 'inform Parties in updating and enhancing $[. .$.$] their actions and support' and to influ-$ ence the next round of NDCs, Parties will have to consider which outcome or combination of outcomes will best achieve these purposes. ${ }^{41}$

\section{Technical Expert Input}

Composed of Member States and including regional and international agencies as observers, the InterAgency Expert Group on SDG Indicators (IAEGSDGs) was established to develop and implement the global indicator framework for the SDGs. The Group then formed three technical working groups to address specific areas relevant to indicator implementation: Statistical Data and Metadata Exchange, Geospatial Information, and Interlinkages. Each group is responsible for their own work plans, methods of work, coordination with other partners and reports on their progress at each of the IAEG-SDGs meetings. $^{42}$

As noted above, UNFCCC Parties have called for the inclusion of IPCC reports in the global stocktake. ${ }^{43}$ A number of Parties also want to replicate or repurpose the Structured Expert Dialogue (SED) that was conducted from 2013-2015 to ensure the scientific integrity of the 2013-2015 review of the agreed long-term global goal to reduce greenhouse gas emissions to hold the global average temperature below $2^{\circ} \mathrm{C}$ above pre-industrial levels. The SED considered relevant scientific information via regular scientific workshops and expert meetings, providing input in to the synthesis reports on the review. ${ }^{44}$

\section{Sharing Knowledge, Information, and Experience}

An aim of the VNR process is to facilitate the sharing of successes, challenges, and lessons learned among governments and to mobilize multi-stakeholder support and partnerships for the implemen- tation of the SDGs. ${ }^{45}$ Through their VNR presentations, countries can share that information and experience on an individual basis. The Regional Forums on Sustainable Development further offer an opportunity for countries to share lessons learned, best practices, and challenges in implementation. ${ }^{46}$

To promote the exploration, analysis, and use of authoritative SDG data sources for evidence-based decision-making and advocacy by Member States, the Open SDG Data Hub serves as a repository for official SDG data and Member States' own open data sites (where available). Its goal is transparent access to enable data providers, managers, and users to better see and communicate trends and relationships out of the wealth of technical information. ${ }^{47}$

UNFCCC Parties are exploring options for supporting databases or platforms for the global stocktake. One possible template is the platform for the Talanoa Dialogue, which publicly stores Party and non-Party submissions in response to the three guiding questions upon which the Dialogue is framed: 'Where are we?', 'Where do we want to go?', and 'How do we get there ${ }^{48}$ Parties could choose to be economical, considering the number of registries that will be established under the Paris Agreement. For example, the Agreement calls for an NDC registry to house NDCs ${ }^{49}$ and an adaptation registry to house Parties' adaptation communications. ${ }^{50}$ If mediated input like synthesis reports will aggregate these sources, yet another registry or platform may not be useful unless it houses additional information that will need to be considered by the global stocktake.

\footnotetext{
40 Draft Conclusions Proposed by the Co-Chairs (n 15) 128-129.

41 Paris Agreement (n 1) art 14(3).

42 United Nations Statistics Division, 'IAEG-SDGs: Inter-agency and Expert Group on SDG Indicators' <https://unstats.un.org/sdgs/iaeg -sdgs/> accessed 15 August.

43 The IPCC is the scientific and intergovernmental council set up under the UN to provide the international scientific consensus on climate change and its political and economic impacts. Decision 1/CP.21 (n 13) paras 21, 99(b), 100

44 UNFCCC 'Report on the Structured Expert Dialogue on the 2013-2015 Review' UN Doc FCCC/SB/2015/INF.1 (4 May 2015).

45 Sustainable Development Knowledge Platform (n 25).

46 United Nations Regional Commissions (n 26).

47 United Nations Statistics Division, 'Welcome to the Open SDC Data Hub' <http://unstats-undesa.opendata.arcgis.com/> accessed 15 August.

48 Decision 1/CP.23 (n 14) 8.

49 Paris Agreement (n 1) art 4(12).

50 ibid art 7(12)
} 
UNFCCC Parties also expect that active engagement in the global stocktake process will facilitate knowledge- and experience-sharing. Under the Paris Agreement's enhanced transparency framework, UNFCCC Parties will be able to engage with one another on their individual NDCs through a facilitative, multilateral consideration of process. ${ }^{51}$ Most likely modelled on the current multilateral assessments and facilitative sharing of views for developed and developing countries, it could consist of a peer questions-and-answers session. However, the means by which Parties can engage and learn from one another during the global stocktake is yet to be determined.

In May 2018, the first Talanoa Dialogue event of the year provided a mix of Parties, intergovernmental organizations and non-state actors the opportunity to literally have a dialogue in small groups, structured around the three guiding questions. These conversations took place over seven parallel sessions in a single day. ${ }^{52}$ Replicating these intimate conversations on a larger scale while still addressing all the workstreams of the global stocktake process would be costly, both in terms of time and expense to Parties and the UNFCCC secretariat.

Another possibility is that a SED-like process could provide an opportunity for Parties to engage with experts and stakeholders in a more structured and focused setting. The SED consisted of fact-finding, face-

51 ibid art 13(11)

52 UNFCCC, 'Summary of the Talanoa Dialogue at the May Sessions' (May 2018) <https://img1.wsimg.com/blobby/go/9fc76f74 -a749-4eec-9a06-5907e013dbc9/downloads/1cgc07t0q_77988 .pdf $>$ accessed 15 August.

53 'Report on the Structured Expert Dialogue on the 2013-2015 Review' (n 42)

54 'Transforming Our World' (n 36) 1, paras 32, 34, 39, 55 and 79.

55 Sustainable Development Knowledge Platform, 'New Online Platform Encourages Global Engagement in Support of Global Goals for Sustainable Development' $<$ https:// sustainabledevelopment.un.org/?page $=$ view\&nr=956\&type $=230$ \&menu=2059 $>$ accessed 15 August.

56 UN Division for Sustainable Development Department of Economic and Social Affairs, 'Handbook for the Preparation of Voluntary National Reviews' (2018) <https://sustainabledevelopment .un.org/content/documents/17354VNR_handbook_2018.pdf $>$ accessed 15 August.

57 Catherine Benson Wahlén, 'DESA Debuts VNR Labs at HLPF 2018' (International Institute for Sustainable Development/SDG Knowledge Hub 9 July 2008) <http://sdg.iisd.org/news/desa -debuts-vnr-labs-at-hlpf-2018/> accessed 15 August.

58 UN General Assembly 'Format and Organizational Aspects of the High-Level Political Forum on Sustainable Development' UN Doc A/RES/67/290 (23 August 2013) para 15.

59 United Nations Statistics Division (n 40). to-face exchanges of views between over 70 experts and Parties over the course of four sessions and was well-received by Parties. ${ }^{53} \mathrm{~A}$ final report summarized discussions and technical information.

\section{Non-State Actor Participation}

The international climate community has increasingly recognized the need for all actors to work towards a better future. While the 2030 Agenda underlines that governments carry the primary responsibility to implement the SDGs, it also states that the scope and ambition of the Agenda requires countries and concerned stakeholders to work together in the implementation and follow-up processes. ${ }^{54}$ Non-state actors in the SDG process are generally limited to the role of observer but can be involved in the SDG process in other ways.

The UN launched the Partnerships for the SDGs online platform as a tool to inform businesses, organizations and individuals, and to encourage global partnerships around the goals. Non-Member stakeholders can find information on initiatives implemented as a result of global partnerships and commitments made to reach the SDGs. ${ }^{55}$

The voluntary VNR guidelines encourage governments to develop a stakeholder engagement plan, identifying key stakeholders across all sectors and levels of government, civil society, the private sector and others, and methods of engagement. ${ }^{56}$ In 2018, the UN experimented with so-called VNR Labs, which provided an informal platform for dialogue between countries, the UN system, and stakeholders. Participants will reflect on how to further improve the VNR process at next year's HLPF. ${ }^{57}$

To the extent that a non-Member stakeholder can engage more formally and directly in the SDG process, the General Assembly resolution on the format and organizational aspects of the HLPF includes a paragraph that sets out ways in which the representatives of major groups of civil society can participate, including intervening in official meetings and presenting written and oral contributions. ${ }^{58}$ International organizations, civil society, academia and the private sector are also invited to participate in the IAEG-SDG groups mentioned above. Subject to the criteria established by each working group, non-state actors can provide technical input to their work on the global indicator framework. ${ }^{59}$ 
How UNFCCC Parties envision the breadth and depth of stakeholder engagement in the global stocktake remains an important open question. The trend since the start of the Paris Agreement negotiations has been for greater involvement of civil society and recognition of sub-national action. The establishment of an online portal cataloguing non-state action, the appointment of Climate Champions, and promotion of the achievements of key sectors at highlevel COP events, indicate a new respect for the role of civil society in effective and global climate action. $^{60}$

If the Talanoa Dialogue is any indication, it is entirely possible that non-state actors could have their voices heard in the global stocktake. A select, representative, and carefully vetted group of non-party stakeholders was invited to participate in the parallel dialogue sessions with negotiators and Party representatives at the May 2018 meeting in Bonn. ${ }^{61} \mathrm{~A}$ similar channel for Party and stakeholder dialogue could be established for the global stocktake. But Parties do not envision that non-state actors will also participate and interact with ministers at the conclusion of the Talanoa Dialogue in December 2018 in Poland. ${ }^{62}$ For civil society to engage at such a high level would be singularly unique to any process under the Convention.

In the same spirit of inviting non-party experts to participate in technical working groups in the SDG process, civil society could engage with Parties through a SED-like process. The focus of the SED would limit the discussion to scientific and technical experts but allow for face-to-face exchanges between them and Parties.

\section{Lessons Learned}

Given that the SDGs process, though relatively new, has several years' worth of experience, are there any lessons learned that UNFCCC Parties can take forward into the negotiations towards the decision text that should be drafted and adopted in Katowice this year?

First, it is worth examining what relevant lessons learned on the SDG review process may have emerged. In examining the feedback from VNR countries, civil society, experts and thought leaders, the UN Foundation has identified four key takeaways. One important result of the voluntary process is that
Parties are valuing early learning over early accountability. Both the UN and governments are learning from their experience in this process and the emphasis on doing so is encouraging openness and change. ${ }^{63}$ A second observation is that embedding civil society and private sector involvement in the VNRs can improve self-reporting, understanding, and reduce duplicative and sometimes critical parallel processes. ${ }^{64} \mathrm{~A}$ third lesson is Parties are more willing to be candid and open about challenges they face if discussed in a 'safe space'. Countries may be less willing to ask for help when opening themselves up to criticism by civil society and media. A challenge is creating an open and balanced but facilitative environment. ${ }^{65}$ The fourth realization is that the process needs to help countries move from plans to impact. Rather than simply restating existing or modest policies, the SDG process needs to incentivize countries to leverage political support, economic resources, and experiences to take real and significant steps forward towards achieving their goals. ${ }^{66}$

Second, it will be important to see what nascent lessons can be learned from the Talanoa Dialogue process, which will conclude at COP 24 . At the same meeting, the modalities and guidelines for the global stocktake process will be adopted. Some early observations can, however, be drawn from the May Talanoa session.

The Talanoa Dialogue's online platform, inclusive dialogues, and a ministerial level event at the COP follow a similar structure to that proposed for the global stocktake. These dialogues featured a broad group of stakeholders that were able to engage with

60 David Wei, 'Linking Non-State Action with the U.N. Framework Convention on Climate Change' (C2ES October 2016) <https:// www.c2es.org/site/assets/uploads/2016/10/linking-nonstate-action -unfccc.pdf> accessed 15 August.

61 'Summary of the Talanoa Dialogue at the May Sessions' (n 50); UNFCCC, 'Sunday Talanoas' < https://talanoadialogue.com/ sunday-talanoas $>$ accessed 15 August.

62 UNFCCC, 'Political Phase' <https://talanoadialogue.com/political -phase $>$ accessed 15 August.

63 Minh-Thu Pham, '4 Lessons Learned Tracking SDG Progress' (UN Foundation 4 July 2018) <http://unfoundationblog.org/4-lessons -learned-tracking-sdgs-progress/> accessed 15 August.

64 ibid. See Adam Fishman, 'SDG Knowledge Weekly: 2018 Highlevel Political Forum, Part 2' (International Institute for Sustainable Development/SDG Knowledge Hub 24 July 2018) <http://sdg.iisd .org/commentary/policy-briefs/sdg-knowledge-weekly-2018-high -level-political-forum-part-2/> accessed 15 August.

65 ibid.

66 ibid. 
one another on the three-question format. ${ }^{67}$ But simply planning for a bigger Talanoa Dialogue in 2023 will neither be manageable nor fulfil the mandate of the global stocktake. Not all Parties felt comfortable engaging in candid dialogue and resorted to stock statements avoiding the articulation of real challenges. Moreover, the three questions that frame the Talanoa Dialogue are not enough to make a meaning ful global assessment of progress on mitigation, adaptation, and support. Eliciting qualitative, narrative responses to these broad questions will not provide a clear snapshot of global greenhouse gas emissions, efforts to adapt to the impacts of climate change, financial flows, and technical and other capacity-building support, nor address the Paris Agreement's imperative to take stock of Parties' implementation in light of the best available science. ${ }^{68}$

Reflections on these two processes can inform the negotiations on the 2023 global stocktake, as well as later iterations, particularly on the key issues identified earlier in this article: How will the global stocktake assess collective progress towards the Paris Agreement's LTGs? How will equity will be operationalized? Has the Paris Agreement elaborated all necessary linkages between the global stocktake and other processes and how do Parties need to define those relationships?

\section{Assessing Collective Progress}

The SDGs process relies on voluntary reporting around sets of indicators. Quantification of some of the information provided can provide a numerical assessment of progress but the UN Secretary-General's final report is still generally an independently

67 UNFCCC, 'Talanoa Sessions' <https://talanoadialogue.com/ talanoa-sessions $>$ accessed 15 August.

68 Paris Agreement (n 1) art 14(1).

69 ibid.

70 See, eg, Shelley Ranii, 'Do Common but Differentiated Responsibilities Belong in the Post-2015 SDGs?' (NYU Center on International Cooperation 21 March 2014); Ingeborg Niestroy, 'Common But Differentiated Governance: Making the SDGs Work' (International Institute for Sustainable Development/SDG Knowledge Hub 21 April 2015) <http://sdg.iisd.org/commentary/guest -articles/common-but-differentiated-governance-making-the-sdgs -work/> accessed 15 August; Jiang Ye, 'The CBDR Principle in the UN 2030 Agenda for Sustainable Development' (China Quarterly of International Strategic Studies 2016).

71 Draft Conclusions Proposed by the Co-Chairs (n 15) 57-58, 61-62. supplemented qualitative assessment because of lack of data, lack of quality data, or the inability to sufficiently aggregate the data provided.

With greater and regular participation, reporting on greenhouse gas inventories in the UNFCCC regime is likely sufficiently comprehensive and robust enough to reasonably assess progress on emissions reductions. However, given the unique and specific nature of adaptation and that the UNFCCC has not previously measured Parties' adaptation efforts, Parties will need to innovate or borrow how they will measure progress towards the new global adaptation goal, like adopting adaptation indicators in order to measure progress on adaptation. The SDG indicators in adaptation-related areas like water or land (SDGs 14 and 15, respectively) could provide useful frames of reference. Another way to integrate adaptation data could be to include regional reports, similar to how the HLPF accepts regional information by the Regional Commissions.

\section{Operationalizing Equity}

The Paris Agreement, in establishing a global stocktake in Article 14(1), states that when the Parties assess collective progress, they shall do so in the light of equity. ${ }^{69}$ Neither the Convention nor the Paris Agreement defines equity, and it is often used in conjunction with or interchangeably with the principle of common but differentiated responsibilities (CBDR), which distinguishes between developed and developing countries with respect to the climate challenge. This concept has, with some resistance, found its way into the SDGs process, as well. ${ }^{70}$ The ways in which it is reflected take several forms.

CBDR in the SDGs can be seen as operationalized in the voluntariness of reporting and because governments can report according to the methodologies as best they can (via tiered indicators). This issue has been similarly raised in the UNFCCC negotiations, as Parties consider flexibility in reporting methodologies for developing countries that need it in light of their capacity and where the IPCC greenhouse gas inventory guidelines also provide for choice in tiered reporting methodologies. ${ }^{71}$

The SDGs themselves can also be considered to capture specific equity-related goals. For instance, SDG 17, which aims to strengthen the means of implementation and revitalize global partnerships, em- 
phasizes the need to build capacity for developing countries. ${ }^{72}$ SDGs 1 and 5, eradicating poverty and promoting gender equality respectively, also promote aspects of equity and mirror CBDR principles reflected in the Paris Agreement. ${ }^{73}$

UNFCCC Parties are still exploring how equity can be meaningfully reflected in the global stocktake process. Some Parties feel that equity is already captured in the structure and the implementation of the Paris Agreement, including in the preambular text that asks Parties to 'respect, promote and consider their respective obligations on human rights, the right to health, the rights of indigenous peoples, local communities, migrants, children, persons with disabilities and people in vulnerable situations, the right to development, as well as gender equality, empowerment of women and intergenerational equity. $^{, 74}$

Other Parties prefer for certain equity elements to be highlighted, such as whether there will be sufficient support for the participation of developing countries or an adequate balance between developing and developed country participation in the global stocktake. ${ }^{75}$ The global stocktake could play a role in enabling donor countries to match with recipient countries where they demonstrate their need. ${ }^{76}$ Other Parties would prefer for equity to be measured, via equity indicators or through an equity framework, with possible reference to historical responsibility. ${ }^{77}$ Still other Parties have suggested that, because it will inform the ambition of future NDCs, the consideration of equity in Parties' NDCs should be assessed or reported in some way. ${ }^{78}$

\section{Linkages}

The structure of the SDGs process is such that Members' voluntary reporting is designed to feed directly into the HLPF and the final report. By contrast, UNFCCC Parties have yet to fully define all the channels and modalities by which information may flow into the global stocktake. The Paris Agreement makes clear that the purpose of the framework for transparency of action is 'to provide a clear understanding of climate action' against its LTGs, including progress towards achievement of Parties' NDCs and their adaptation actions to inform the global stocktake. ${ }^{79}$ The framework for transparency of support is to 'provide clarity on support provided and re- ceived' and a full overview of aggregate financial support provided to inform the global stocktake. ${ }^{80}$

However, the links between the transparency frameworks have yet to be made operationally clear. Parties must tackle how individual mitigation, adaptation, and financial data are submitted in a meaningful way to the stocktake. For example, if individual greenhouse gas inventories, adaptation communications, and financial reports are transmitted directly to the global stocktake, they will have to be further synthesized to make a global assessment. Alternatively, Parties could decide that those inputs will be aggregated by an assigned body and those synthesis reports transmitted to the global stocktake as inputs. Parties have yet to articulate these roles and responsibilities. $^{81}$

The global stocktake could also potentially link to other processes not explicitly mentioned by the Paris Agreement. For example, Parties could decide that reports from the Article 15 implementation and compliance mechanism could feed into the global stocktake, informing Parties of gross or systematic noncompliance issues. $^{82}$

In the latter of these two issues, the SDGs and Paris Agreement processes may simply be far too dissimilar to draw comparable lessons. However, there are other points of comparison that merit some consideration.

Both processes encourage and rely on receiving more and better data over time. In the introduction to the Secretary-General's 2018 SDGs report, he emphasizes that the 'availability of quality, accessible, open, timely and disaggregated data is vital for evidence-based decision-making and the full implementation of the 2030 Agenda [...] To meet these data de-

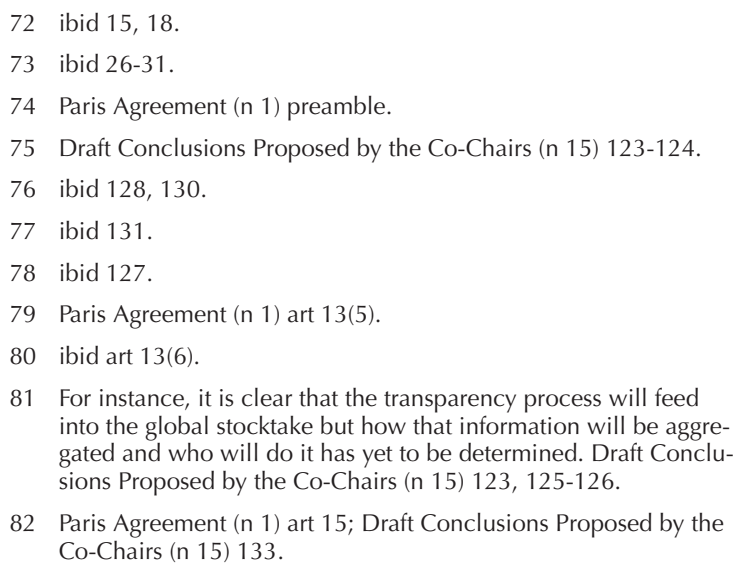


mands there is an urgent need to strengthen the capacities of national statistical systems. ${ }^{83}$ Without robust information, it is difficult to ascertain whether countries are individually or collectively meeting their targets. Both processes also accept that many countries, especially developing countries with less or limited capacity, will struggle with reporting regularly and robustly. They recognize the need to build their capacity to improve their reporting over time.

The Paris Agreement also places a strong emphasis on building domestic capacity for reporting and review and the current negotiations on the modalities, procedures and guidelines for the enhanced transparency framework reiterate the Agreement's vision of improvement over time. ${ }^{84}$ To help developing countries, the Agreement established the Paris Committee on Capacity-Building to facilitate capacity-building generally ${ }^{85}$ and the Capacity Building Initiative for Transparency, specifically to 'build institutional and technical capacity' for developing countries to meet the enhanced transparency requirements and to 'assist in the improvement of transparency over time. ${ }^{86}$

Arguably, hosting the HLPF every year, even if at the head of state level every few years, diminishes the political impact of the SDG outcomes, as compared to the global stocktake. The HLPF culminates annually in a public event and UN Secretary-General report. All of the SDGs are not reviewed every year and only those Parties that wish to be reviewed volunteer

83 ECOSOC (n 21) para 4

84 Draft Conclusions Proposed by the Co-Chairs (n 15) 55, 58, 68.

85 Decision 1/CP.21 (n 13) para 71.

86 ibid para 85(c).

87 Paris Agreement (n 1) art 14(3).

88 China, 'China's Input on Talanoa Dialogue' (UNFCCC Talanoa Dialogue Platform 2 April 2018) $5<$ https://unfccc.int/sites/default/ files/resource/104_China\%C3\%A2\%E2\%82\%AC\%E2\%84\%A2s \%20inputs\%20on\%20Talanoa\%20Dialogue.pdf> accessed 15 August.

89 The UN Office for Disaster Risk Reduction, 'Sendai Framework for Disaster Risk Reduction 2015-2030' (2015) < https://www.unisdr .org/files/43291_sendaiframeworkfordrren.pdf> accessed 15 August.

90 UNFCCC Secretariat, 'Opportunities and Options for Integrating Climate Change Adaptation with the Sustainable Development Goals and the Sendai Framework for Disaster Risk Reduction 2015-2030' (2017) < https://unfccc.int/sites/default/files/resource/ techpaper_adaptation.pdf $>$; Adam Fishman, 'UNFCCC Expert Meeting Compares National Adaptation Goals to SDGs, Sendai Framework' (International Institute for Sustainable Development/SDG Knowledge Hub 7 August 2018) <http://sdg.iisd.org/ news/unfccc-expert-meeting-compares-national-adaptation-goals -to-sdgs-sendai-framework/> accessed 15 August.

91 Fishman (n 64). to do so. Member States are encouraged but not obliged to take forward lessons from the HLPF and report into their policy planning and monitoring processes.

The outcome of the global stocktake, however, should have significant gravity: it is meant to 'inform Parties in updating and enhancing, in a nationally determined manner, their actions and support [...], as well as enhancing international cooperation for climate action' ${ }^{87}$ This event, intended to occur every five years, ought to enhance the ambition of Parties' next NDCs, which will account for the next five or ten years of their efforts under the climate regime. These NDCs, in turn, will have a substantial impact on domestic litigation and policy, business and corporate planning and decision-making, multilateral partnerships, and global financial flows. Such an event will require a host of resources and political capital that should be spent strategically on a process meant to be a regular and powerful driver to greater global action and support over time.

\section{The SDGs/HLPF and Global Stocktake: Complementary versus Distinct Processes}

Given the differences between the two processes, can they become complementary? A number of actors have considered this possibility, ${ }^{88}$ recommending the alignment of adaptation under the Paris Agreement and UNFCCC with related SDG indicators, as well as the indicators in the Sendai Framework on Disaster Risk Reduction, a 15-year, voluntary, non-binding agreement to reduce disaster risk and losses in lives, livelihoods and health. ${ }^{89}$ In a recent expert meeting with Parties and in a technical paper, the UNFCCC Secretariat and the Adaptation Committee have explored how to improve coherence between the three frameworks to save money and time, enhance efficiency, and further enable adaptation action. ${ }^{90}$

However, further integration of adaptation plans with the SDGs and the Sendai Framework can entail challenges regarding data, conflicting mandates between lead agencies, opposing policies, lack of standardized definitions, and gaps in monitoring. ${ }^{91}$ Moreover, alignment would need to overcome most UNFCCC Parties' and experts' lack of familiarity with the SDGs and Sendai Framework processes as well as the tendency toward political entrenchment within climate regimes. 
Both the SDGs and global stocktake processes will continually evolve as countries improve their reporting, incorporate more robust data, and tweak processes and outputs to make them fit for purpose: obtaining the information necessary to determine whether countries are making actual and effective progress towards global goals. Both processes emphasize the need for better governance and information management systems, which call for better intergovernmental coordination, the mainstreaming of climate change action and sustainable development, and the reframing of priorities of 'non-climate' ministries and departments to fall in line with or complement climate change laws and policies. Parties could begin to look to the long-term integration of aspects of both regimes to enhance coherence and reduce redundancies over time.

\section{Conclusion}

The Paris Agreement's global stocktake is a unique multilateral review process, incorporating increasingly regular and robust individual country reports and internationally vetted scientific data to make an assessment of global progress towards the goals of the Agreement. It is a crucial feature of the facilitative accountability framework underpinning the careful balance between top-down obligations and bottom-up national determination that sets the Agreement apart from other conventionally punitive international accords. In taking stock of collective action and progress, and sharing challenges, lessons learned, and successes, it further lays the foundation for greater ambition, collaboration, and improvement over time.

At COP 24, Parties will need to narrow the broad outlines of how they currently envision the global stocktake down to specifics. Cycles need to be defined and ways to aggregate the vast amounts of information must be determined. Although the Talanoa Dialogue has yet to conclude and elements of the SDG process are unique in their own right, Parties can begin to draw on their parallels and any early lessons they offer as they consider now what key features to include in the modalities, rules, and guidelines to be decided at the December 2018 climate conference in Katowice, Poland.

All need not be decided in one go. Parties can and likely should further evolve and fine-tune the process in the future. Given that the Paris Agreement asks governments to endeavour to continuously improve over time, negotiations on the global stocktake are unlikely to be finished in their entirety in Katowice. The Bonn informal notes indicate that Parties are considering how and when they want to revisit modalities of the stocktake, such as refining its procedural and logistical elements on the basis of experience and reviewing and updating the list of inputs to the stocktake, as appropriate, two years prior to the next global stocktake. ${ }^{92}$ Like other reviews in the UNFCCC, Parties can decide to dedicate regular moments to revisit and update key aspects of the mechanism, taking into account, for instance, experience gained and the latest science.

The global stocktake is a key piece of the foundation for the Paris framework. The modalities decided in Katowice this year will lay the groundwork for a process that can carry forward the current political momentum and contribute to defining the legacy of the Paris Agreement, ultimately giving it the robustness, ambition, and durability that Parties envisioned in Paris.

92 Draft Conclusions Proposed by the Co-Chairs (n 15) 124 and 130. 